\title{
Influence of conventional and modern scheme of extraction and solvents on phytochemicals and biological activities of Sphaeranthus indicus
}

\author{
Sobia Noreen ${ }^{1 *}$, Fozia Batool ${ }^{1}$, Bushra $\mathrm{Ijaz}^{2}$, Momina Hussain ${ }^{1}$ and \\ Fatima Bilal ${ }^{1}$ \\ 1. Department of Chemistry, University of Sargodha, Sargodha-Pakistan \\ 2. Centre of excellence in molecular biology, Lahore-Pakistan \\ *Corresponding author's email: sobianoreen@uos.edu.pk
}

Citation

Sobia Noreen, Fozia Batool, Bushra Ijaz, Momina Hussain and Fatima Bilal. Influence of conventional and modern scheme of extraction and solvents on phytochemicals and biological activities of Sphaeranthus indicus. Pure and Applied Biology. Vol. 6, Issue 3, pp776-785. http://dx.doi.org/10.19045/bspab.2017.60082

\begin{tabular}{llll}
\hline \hline Received: 23/04/2017 & Revised: 05/06/2017 & Accepted: 12/06/2017 & Online First: 15/06/2017 \\
\hline
\end{tabular}

\section{Abstract}

Present study was based upon the phytochemical screening, antimicrobial and antithrombotic potential of a traditional herb Spharenthus indicus (commonly called East Indian globe thistle). A range of solvents from non-polar to polar (n-hexane, ethyl acetate, methanol) were used to attained the extract by employing conventional and modern methods of extraction like orbital shaker assisted extraction, decoction and microwave assisted extraction in order to check their effect on concentration of phytoconstituent and biological activities. Percentage yield was varied from 2.01 to $30.05 \%$ of dry weight. Phytochemical screening provides a detailed profile in plant matrix like tannins are present in methanol and ethyl acetate extracts while absent in n-hexane extracts. Flavonoids, phenols and saponins are present in methanol, ethyl acetate and n-hexane extracts in decreasing order. Cumarins are present in high amount in methanol extracts. The antibacterial test was applied on all extracts of plant and the larger zone of inhibition was found against $S$. typhi $18.9 \pm 0.4(\mathrm{~mm})$ for microwave extract of methanol. The thrombolytic activity of S. indicus showed greater activity of $80 \%$ for methanol extract (microwave assisted). This work emphasizes the consideration of microwave assisted extraction on the basis of scientific evidence in order to utilize $S$. indicus for the basic and applied research of biology.

Keywords: Spharenthus indicus; Orbital shaker; Decoction; Microwave assisted extraction; Phytochemicals; Antibacterial activity

\section{Introduction}

The man curiosity for search of natural drug has long history, of which there is plenty of evidence from many sources: preserved monuments, written documents, and even original plant medicines. The struggles of many years against illness gave us in result the awareness of medicinal plants that is how man learned to hunt drugs in, seeds, barks, fruit, and additional parts of the plants. Usually plant based medicine are functional by self-medication or 
recommended by general practitioner or pharmacist. These medicines are considered safe for public because these are obtained by natural sources [1]. The synthetic drugs and antibiotics have some limitations: First of all, these medicines are of high cost and due to which out of range from a common patient of developing countries. Secondly, the antibiotics become ineffectual by the time because microorganisms gain resistance in opposition to antibiotics $[2,3]$. Moreover the antibiotics also involve unpleasant effects on the host, for example, immune suppression, allergic reactions and hypersensitivity. Natural products make his way via friendliness nature to discover new antibiotics $[4,5]$.

Sphaeranthus indicus Linn belongs to family Asteraceae. The plant is distributed all over the wet lands and also in plain areas of Pakistan, Sri Lanka, India and Australia [6]. The plant is involved to treat epileptic convulsions, mental illnesses, leprosy, hemicranias and as nervine tonic [7]. It is used to treat conditions of jaundice, piles, hepatitis, hepatopathy, diabetes, fever, pectoralgia, cough, gastropathy, hernia, hemorrhoids, helminthiasis, dyspepsia and skin diseases such as pruritus and edema. Plant root oil reported to be useful in curing scrofula. The paste of this herb is advantageous in treating arthritis, filariasis, gout and cervical adenopathy [8].

The role of solvent and extraction procedure is considered significant for standardization of phyto extract as it affect the physical and chemical properties of phytoconstituents. A range of conventional techniques including maceration, percolation, decoction infusion are now replaced by modern age green extraction schemes like Ultrasonic assisted extraction (UAE), supercritical fluid extraction (SFE) and Microwave assisted (MAE) etc. $[9,10]$. The MAE is eco friendly in term less consumption of solvent and energy and gives the best yield of phytoconstituents either equivalent or greater than the conventional methods [1113].

Keeping in view the effect of extraction procedure and solvent type present investigation was carried out on phytoconstituents of Sphaeranthus indicus under different conditions in order to compare the effect of different nature solvents and scheme of analysis (conventional and modern).

\section{Material and methods}

\section{Chemicals}

All the chemicals and reagents used were of analytical grade and purchased from E. Merck or Sigma-Aldrich otherwise specified. Solvents of analytical grade were used for extraction, tests of phytoconstituents and biological activities like Methanol (MeOH), n-hexane, Chloroform $\left(\mathrm{CHCl}_{3}\right)$, Ethyl acetate (EtOAc), Ferric chloride, Potassium mercuric chloride, Sulphuric acid, ammonia, Ammonium hydroxide, Benzenel, Ether, Hydrochloric acid, Sodium hydroxide, Streptokinase, Muller Hinton agar media .

\section{Sample selection and preparation of} different extracts

On the basis of rich medicinal history of $S$. indicus sample was purchased from the local market of Sargodha, Pakistan and further authenticated by a taxonomist of department of Botany University of Sargodha, Sargodha, Pakistan. After manual cleaning by hand picking, seeds were washed with excess of fresh water followed by treatment with deionized water to remove soluble impurities. Manually cleaned and dried (ambient conditions) sample was ground in electrical stainless steel grinder (LG BL 999SP) to fine powdered form. The powder was stored in air tight glass jar till further analyses.

Phytoconstituents of the sample were extracted using different solvents (n-hexane, ethyl acetate, $80 \%$ methanol). Solid liquid 
ratio (sample: solvent) was taken as 1:10 w/v. Three extraction procedures (conventional and modern); orbital shaking (OS), decoction (DE) and microwave assisted extraction (MAE) were selected for comparative extraction. In case of orbital shaking $10 \mathrm{~g}$ of sample was soaked in 100 $\mathrm{mL}$ of each solvent and agitated for $6 \mathrm{~h}$ at room temperature on shaker (Optima orbital shaker OS-752). In decoction, $10 \mathrm{~g}$ of sample was boiled in $200 \mathrm{~mL}$ of solvents for 30 min followed immediately by cooling. MAE of sample was done at power of $90 \mathrm{~W}$ for 15 min while OAE at speed of 150 for 3 h. At the end extract was left for temperature stabilization then supernatant recentrifuged and concentrated. Successive extraction was followed thrice and finally separated components were filtered by whatman filter paper No.1. Filtrates were concentrated in rotary evaporator (Buchi Rotavapor R-200) under vacuum at $45{ }^{\circ} \mathrm{C}$. Sticky semisolid was obtained that were stored in airtight vials and store at $4{ }^{\circ} \mathrm{C}$. Prior to storage percentage yield was calculated. Following formula was used to calculate yield of each extract in order compare the effect of solvent type and extraction techniques.

$\%$ age Yield $=$ Mass of extract $/$ Mass of sample x 100

Qualitative analysis for phytochemical

Preliminary screening was completed by following reported methods [14-16].

\section{Saponins}

This test also called foam test. Extract was mixed in water and subjected to continous shaking form is produced and persist for 10 min, shows the presence of saponins.

\section{Tannins}

Extract was diluted by adding $1.00 \mathrm{~mL}$ of water in $0.5 \mathrm{~mL}$ of sample. Few drops of ferric chloride added to the test tube in test mixture. Blue colour was appeared to confirm the presence of Gallic tannins and catecholic greenish black color confirmed the presence of catecholic tannins.

\begin{abstract}
Alkaloids:
Small amount of Meyer's reagent (Creamish white precipitate)/ Wagner reagent (reddish brown precipitate) was poured in $1.00 \mathrm{~mL}$ of extract that confirmed the alkaloids.
\end{abstract}

\section{Terpenoids}

(Salkowski test): Chloroform containing $5.00 \mathrm{~mL}$ extract was mixed with $3.00 \mathrm{~mL}$ of cocn. $\mathrm{H}_{2} \mathrm{SO}_{4}$. Terpenoids were confirmed by reddish brown color.

\section{Flavonoids}

Small amount of extract was mixed with $\mathrm{NaOH}$ solution. Intense yellow color which became colorless that pointed out flavonoids presence.

\section{Fatty Acids}

Solution of $0.5 \mathrm{~mL}$ extract in $5.00 \mathrm{~mL}$ ether was poured on filter paper and allowed to evaporate. Transparent spots indicated occurrence of fatty acids.

\section{Anthocyanins}

Extract solution was mixed with ammonia and few drops of $2 \mathrm{~N} \mathrm{HCl}$. Pink-red/ blue violet color indicated anthocyanins.

\section{Anthraquinones}

To check anthraquinones benzene $(10.00 \mathrm{~mL})$ was mixed with $(0.5 \mathrm{gm})$ of each plant extract and shaken well and then (5.00 $\mathrm{mL}$ ) of $10 \%$ ammonia was added after filtration. Red/pink to violet colors showed presence of anthraquinones.

\section{Coumarins}

Measured $3.00 \mathrm{~mL}$ of $10 \% \mathrm{NaOH}$ was added in $3.00 \mathrm{~mL}$ of extract, yellow color indicates the presence of cumarins.

\section{Emodins}

$\mathrm{NH} 4 \mathrm{OH}(2.00 \mathrm{~mL})$ was added in $3.00 \mathrm{~mL}$ of benzene along with small amount of extract. Red color confirmed the emodins in samples.

\section{Biological activities}

\section{Antithrombotic activity}

For evaluation of thrombolytic activity 5.00 $\mathrm{mL}$ of distilled water was shaken carefully with commercially available Streptokinase. This stock solution was used for in vitro 
antithrombotic activity. Extracts were soaked in distilled water for overnight. Supernatants were separated by filtration using 0.22 micron syringe filter paper. Blood samples were collected from healthy volunteer and stored in pre-weighted sterilized and labeled vials. All sample vials were incubated for $45 \mathrm{~min}$ at $37{ }^{\circ} \mathrm{C}$ for clotting. Vials were again weighted after removing serum carefully from clot. Weight of clot was calculated by following formula.

Weight of clot $=$ weight clot carrying tube weight of empty tube

About $100 \mu \mathrm{L}$ of each extract was added to clots, Streptokinase (positive control) and distilled water (negative control). All mixtures were incubated at $37{ }^{\circ} \mathrm{C}$ for $90 \mathrm{~min}$. Fluid was removed and samples were weighted again. Percentage lysis was determined with respect to control [17].

\section{Antibacterial activity}

Antimicrobial susceptibility test was done by disc diffusion method [18]. For growing strains Muller Hinton agar media was used. Apparently agar was transparent and light yellowish-brown in color. For the preparation of media, $34.00 \mathrm{gm}$ of Muller Hinton ground agar was weighed and dissolved in $1 \mathrm{~L}$ of distilled water and mixture was allowed to sterilize by using autoclave at $121^{\circ} \mathrm{C}$ for $20 \mathrm{~min}$. The media was shifted instantly in sterile Petri plates, allowed to cool and was kept at the room temperature in order to solidify.

Every bacterial culture was streaked on nutrient agar to obtain single colonies and incubated overnight at $37{ }^{\circ} \mathrm{C}$. After incubation, one or two single colonies and inoculate in $0.85 \%$ saline solution and adjusted the turbidity to meet the 0.5 McFarland turbidity standards. The $10 \mu \mathrm{L}$ bacterial suspensions were spread on agar medium with the help of sterilized micropipette. Petri plates were revolved to distribute bacteria evenly. The extracts of sample are diluted to estimate the antibacterial activity. The sterilized discs of filter paper $(5.00 \mathrm{~mm})$ were cut and loaded with diluted extracts and ciprofloxacin as standard antibacterial drug. The extract soaked filter paper discs were put on the agar surface. The plates were incubated for $24 \mathrm{~h}$ at $37{ }^{\circ} \mathrm{C}$. Antibacterial activity was measured in terms of inhibition zones in $\mathrm{mm}$.

\section{Statistical analysis and data presentation}

Statistical interpretations of experimental data (all in triplicate) were articulated as mean \pm standard deviation. Results were executed in particular via Graph Pad Prism version 5.00 for Windows, San Diego California USA and Minitab 17.

\section{Results and discussion Percentage yield}

Solid/liquid extractions are most efficient but yield of any extraction method depends upon many factors including nature of solvents and sample, their quantity and applied physical parameters. Detail of yields of all extracts obtained in different solvents by applying three different extraction techniques is given in Figure 1. Analysis of percentage yield indicates that polar solvents are better than non-polar solvents for extraction of phytoconstituents from $S$. indicus seeds. Yield varies from $2.41 \%$ in n-hexane to $40.84 \%$ in $80 \%$ methanol. Maximum yield was shown by $80 \%$ methanolic extracts attributing that addition of water increases efficiency of extraction. It reveals that polarity index acts as an enhancement tool for extraction of constituents from plants. This trend is similarly reported by Khan et al. [19]. It is observed from percentage of various extracts that MAE is more efficient method of extraction than orbital shaking and decoction for $S$. indicus because high yield of extracts. Results also strengthen the concept that polar solvents are better for extraction of $S$. indicus. The reason behind high yield of MAE is the effect of direct 
heat that has strong impact on heating kinetics that exert pressure on cell wall and cell membrane structures thus enhancing the diffusion/partition rate of the solute onto plant matrix $[20,21]$. While in conventional methods the shift of heat is either through convection or conduction from the surface of material. Solvent ability of extraction depends upon phytochemical solubility, mass transferring kinetic and solute strength $[22,23]$.

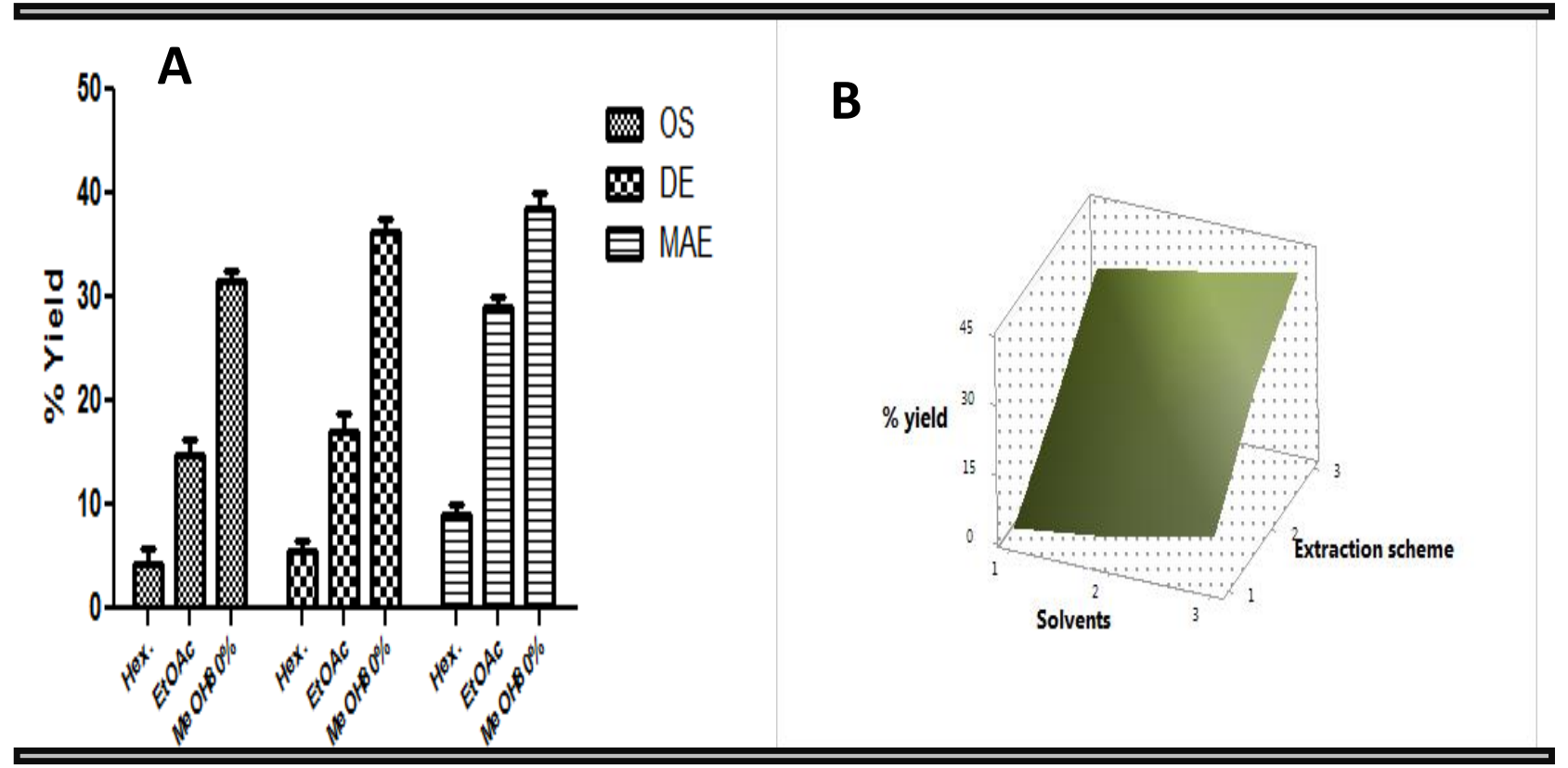

Figure 1. Extraction yield of $S$. indicus extracts obtained in different solvents and different techniques. (A: \% age yield in the form of bar graph: B: \%age yield represented in form of response surface methodology $(\mathrm{RSM}))$. (1)OS: orbital shaker assisted extraction,(2)DE: Decoction extraction, (3)MAE: Microwave assisted, (1)Hex: Hexane, (2)ETOAc: Ethylacetate, (3)MeOH80\%: $80 \%$ methanol. Values are average $(n=1 \times 3)$ and represented as mean \pm SD

\section{Qualitative analysis for phytochemical}

Biologically active compounds are extracted by using solvents of different polarity ad based upon the rule of "like dissolve likes". Phytochemical screening of different extracts is very simple, time saving and inexpensive [24]. Tannins have significant stringent properties. They are important for healing inflamed mucous membrane and dermal wound. Flvonoids are free radical scavenger and water soluble antioxidants. It has strong anticancer activity and oxidative cell damage. It also helps to manage oxidative stress induced by diabetes. Terpenoids are remarkably useful in curing many diseases [25]. In addition it also possesses insecticidal properties and has the potential to use in stores of agriculture products [26]. These results of phytochemical screening of $S$. indicus are given below in Table 1. 
Table 1. Phytochemical screening of S.indicus in different solvents and varying techniques

\begin{tabular}{|l|c|c|c|c|c|c|c|c|c|}
\hline Phytoconstituents & \multicolumn{3}{|l}{ Orbital shaker } & \multicolumn{3}{|l|}{ Decoction } & \multicolumn{3}{l|}{$\begin{array}{l}\text { Microwave assisted } \\
\text { extraction }\end{array}$} \\
\hline & MeOH & EtOAc & Hex. & MeOH & EtOAc & Hex. & MeOH & EtOAc & Hex. \\
\hline Tanins & ++ & + & - & ++ & + & - & +++ & + & - \\
\hline Saponins & ++ & + & + & ++ & + & + & ++ & + & + \\
\hline Flavonides & ++ & + & + & ++ & + & + & ++ & + & + \\
\hline Phenols & +++ & + & + & +++ & ++ & + & +++ & + & + \\
\hline Terpenoids & - & - & - & - & - & - & - & - & - \\
\hline Fatty acids & ++ & + & + & ++ & + & + & ++ & + & ++ \\
\hline Anthocyanin & - & - & - & - & - & - & + & - & - \\
\hline Anthraquinone & - & - & - & - & - & - & + & - & - \\
\hline Coumarins & +++ & + & - & +++ & + & - & +++ & + & - \\
\hline Steroids & + & - & - & ++ & - & - & + & - & + \\
\hline
\end{tabular}

+++ Very intense color, ++ medium dark color, + presence, - absence

\section{In Vitro clot lysis activity}

Thrombosis is a disease in which clotting of blood takes place in circulatory system of body. This phenomenon can lead to deep vein thrombosis, cerebral infarction, heart attacks, pulmonary amboli, Strocks and vascular blockage which can cause even death. The drugs streptokinase (SK) and urokinase (UK) are used usually for treatment, but these drugs have major side effects i.e. hemorrhage, fibrinolysis anaphylactic reaction [27]. Due to these risks of side effects there is a need of another alternative. The research is been carried out to check the antithrombic potential of $S$. indicus to get the natural source to control thrombosis. The results are reported to show the antithrombic activity of methanol, ethyl acetate and n-Hexane extracts treating with two techniques (orbital shaker and decoction) (Figure 2). The relation of extraction scheme and solvents with the antithombotic activity was also studied by the Pearson correlation that indicate that amount of phyto constituent in term of percent yield of specific scheme is strongly correlated with the biological activity. The results obtained were $\mathrm{r}^{2}=0.999$ $r^{2}=0.997$ and $r^{2}=0.754$ in case of orbital shaker extraction, decoction and microwave assisted extraction respectively. These findings were in agreements that solvent type and extraction scheme strongly influence the amount of phytochemicals and in turn biological activities. 


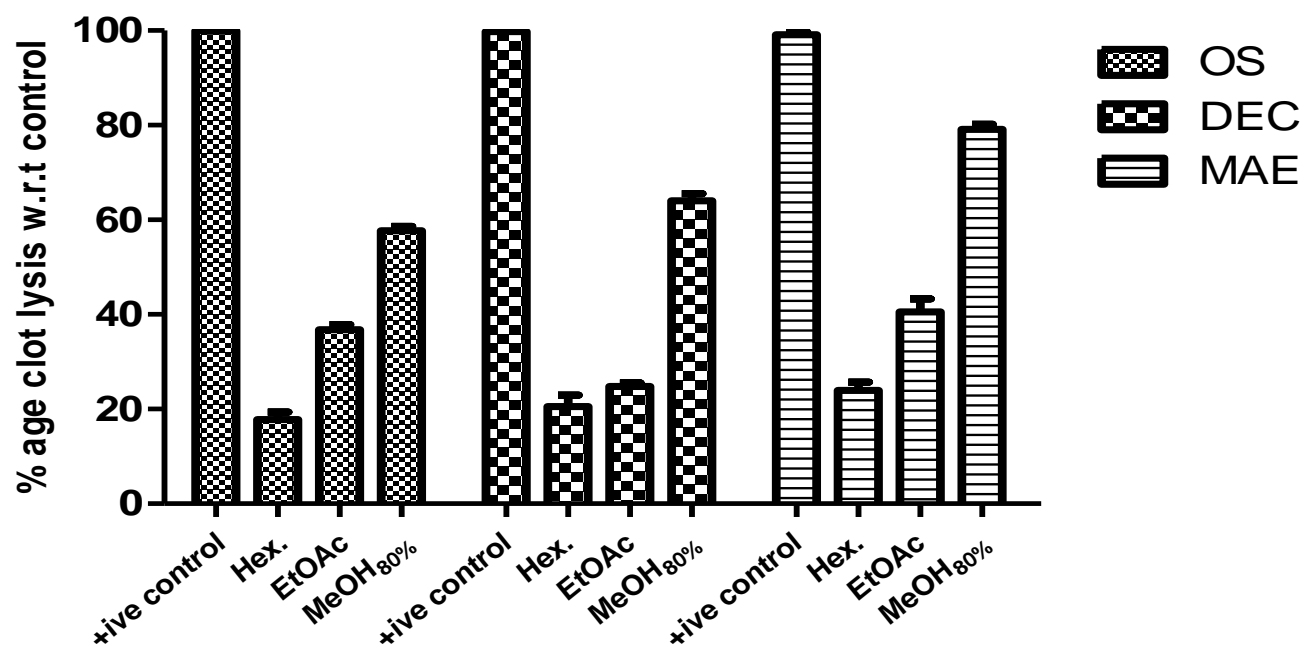

Figure 2. Antithrombotic activity (Percent) of seeds extracts of S.indicus and standard. Means and standard deviations were of triplicate. Bars denote a significant difference between treatments $(p<0.05)$

Antibacterial activity of extracts of $S$. indicus

Amplified bacterial resistance against presently available synthetic antibiotics has forced researcher for exploring of novel safe agents [28]. Different antibiotics put into practice their inhibitory action on diverse population of pathogens [29]. Indiscriminate use of commercially offered drugs against infectious pathogens has become the main cause of development of multiple drug resistance in human.

Antibacterial activity of plant $S$. indicus shows that plant is resistance against certain bacteria and can be used for medicinal purpose. Methanolic extract of decoction showed the inhibition zone of $16.0 \pm 0.2$,
$15.0 \pm 0.4, \quad 14.4 \pm 0.5$ and $16.5 \pm 0.4$, for Escherichia coli, Salmonella typhi, Staphylococcus aureus and Bacillus subtilis respectively. Microwave assisted extracts exhibit the best inhibition zone for all stains as compare to orbital shaker and decoction. Ethyl acetate and N-hexane extracts of orbital shaker following the same trend and gave batter zones then decoction treated extracts. As a whole all methanolic extracts exhibited larger zone while smaller zone in case of n-Hexane. A comparative view for activities of all sample extracts to Ciprofloxacin in terms of percentage inhibition with respect to standard against all strains of bacteria is given in Table 2 and Figure 3 and 4.

Table 2. Diameter of inhibition zone $(\mathrm{mm})$ for $S$. indicus. Values are means $\pm \mathrm{SD}(\mathrm{n}=3)$ of three separate experiments

\begin{tabular}{|l|l|l|l|l|l|l|l|l|l|}
\hline \multicolumn{4}{|l|}{ Orbital shaker } & \multicolumn{3}{l|}{ Decoction } & \multicolumn{3}{l|}{ Microwave assisted extraction } \\
\hline & Hex & EtOAc & $\mathbf{M e O H}_{\mathbf{8 0} \%}$ & Hex & EtOAc & $\mathbf{M e O H}_{\mathbf{8 0} \%}$ & Hex & EtOAc & MeOH$_{80 \%}$ \\
\hline E. coli & $7.24 \pm 0.6$ & $12.3 \pm 0.3$ & $19.46 \pm 0.3$ & $12.9 \pm 0.2$ & $10.6 \pm 0.1$ & $16.0 \pm 0.2$ & $9.46 \pm 0.3$ & $12.3 \pm 0.3$ & $17.24 \pm 0.6$ \\
\hline S.typhi & $7.9 \pm 0.4$ & $12.8 \pm 0.8$ & $17.7 \pm 0.6$ & $11.1 \pm 0.4$ & $7.8 \pm 0.2$ & $15.0 \pm 0.4$ & $9.7 \pm 0.6$ & $13.8 \pm 0.8$ & $18.9 \pm 0.4$ \\
\hline S aureus & $3.1 \pm 0.1$ & $7.4 \pm 0.2$ & $11.1 \pm 0.03$ & $8.3 \pm 0.1$ & $7.03 \pm 0.5$ & $14.4 \pm 0.5$ & $4.1 \pm 0.03$ & $7.4 \pm 0.2$ & $16.4 .1 \pm 0.1$ \\
\hline B. subtilis & $6.4 \pm 0.3$ & $8.5 \pm 0.05$ & $12.1 \pm 0.1$ & $7.8 \pm 0.4$ & $5.5 \pm 0.7$ & $16.5 \pm 0.4$ & $8.1 \pm 0.1$ & $11.5 \pm 0.05$ & $13.4 \pm 0.3$ \\
\hline $\begin{array}{l}\text { Positive } \\
\text { control }\end{array}$ & $20.1 \pm 0.1$ & $20.4 \pm 0.2$ & $21.1 \pm 0.03$ & $20.3 \pm 0.1$ & $20.03 \pm 0.5$ & $20.24 \pm 0.6$ & $20.3 \pm 0.3$ & $21.46 \pm 0.3$ & $20.9 \pm 0.2$ \\
\hline
\end{tabular}



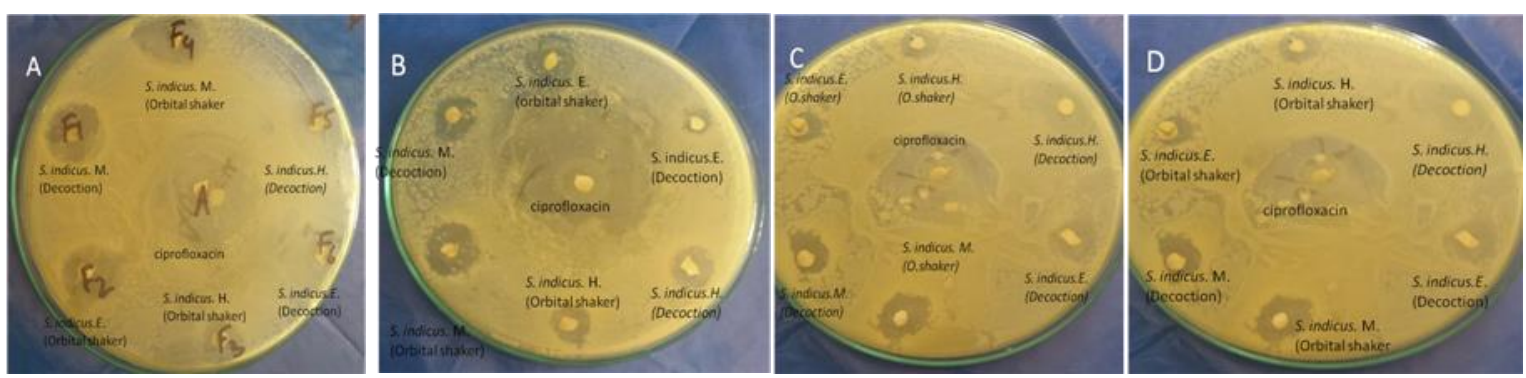

Figure 3. Zone of inhibition (antimicrobial effect) by different extracts of $S$. indicus (A) on $E$. coli (B) on S. typhi (C) on S. aureus; (D) on B. subtilis

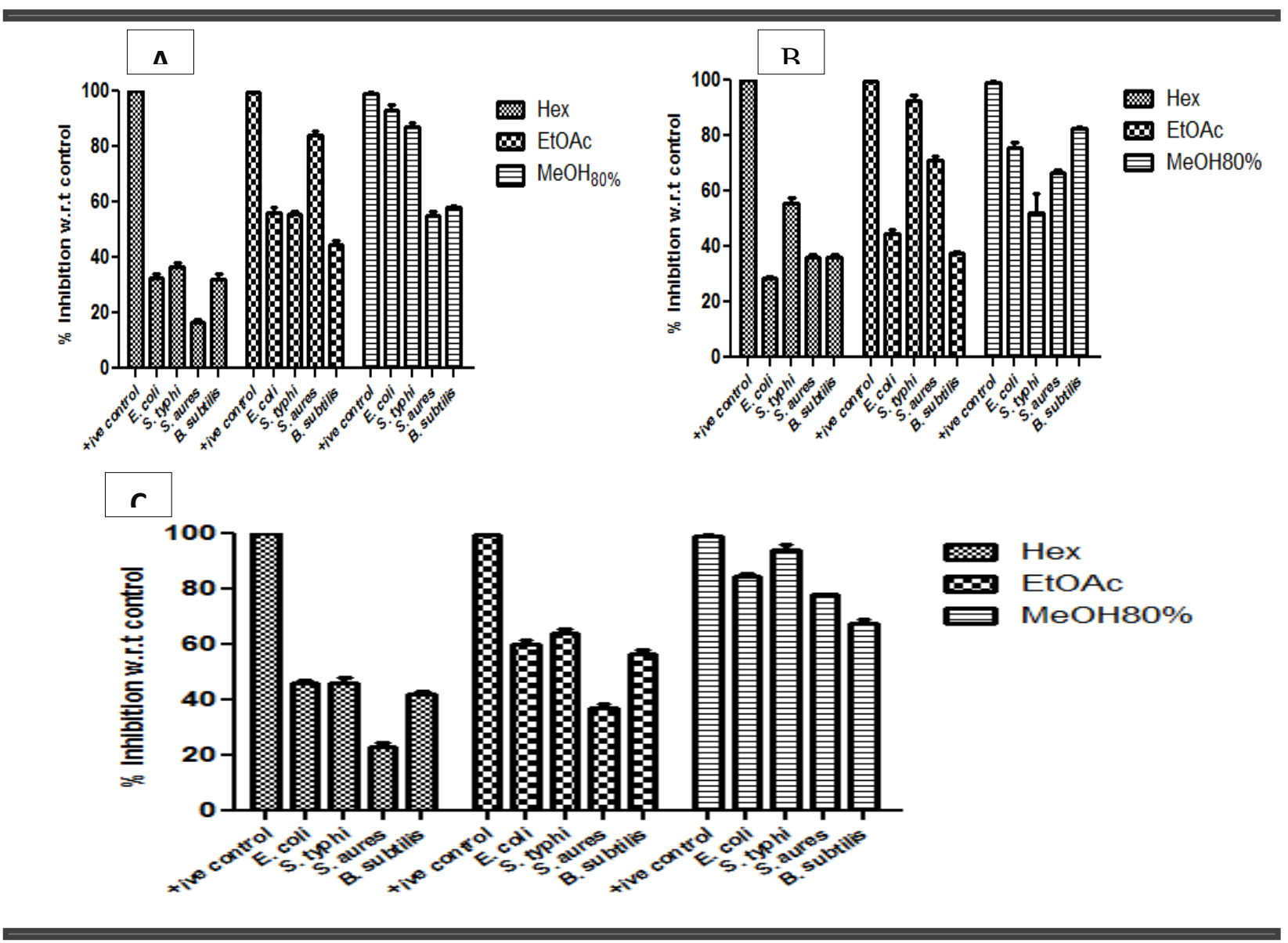

Figure 4. Comparison of percentage inhibition of $S$. indicus extracts prepared by three techniques and different solvents against E.coli, S. aureus, B. subtilis and S. typhae with respect to control . (A) OS: orbital shaker assisted extraction, (B) DE: Decoction extraction, (C)MAE: Microwave assisted, Hex: Hexane, ETOAc: Ethylacetate, MeOH80\%: 80\% methanol. Values are average $(n=1 \times 3)$ and represented as mean $\pm S D$

\section{Conclusions}

In today's modern age the development of best standard method for rapid and efficient extraction of constituents from plant matrix is become challenging cumbersome task due to intrinsic constraint of conventional procedure. Appropriate choice of extraction method and solvents influences efficiency of 
extraction. Present findings clearly indicated that $S$. indicus revealed the noteworthy concentration of active constituents in different extraction procedures. Nine experimental runs in which the effect two independent variables (3 levels of each) on the dependent variables (percent yield and total constituents were performed. All experiments were performed in triplicate. Interestingly all the best results in term of \% yield, phytochemicals concentration and their biological activities were displayed by aqueous methanolic extract of MAE method. The results specified that microwave assisted extraction can be practicable alternatives for conventional extraction method. Origin of this resistance is multifactorial which may be due to specific nature of the association between bacteria and antibiotics, the dose of antibacterial agent, environmental factors and host characteristics. These circumstances has forced researchers to explore new antimicrobial agents of variable origins as novel chemotherapeutical agents against bacteria but manufacturing cost for these synthetic drugs is very high and they may be cause of adverse effects as compared to herbal antimicrobial drugs. This entire scenario has made medicinal plants as a safe and cheap source of such type of medicines.

\section{Authors' contributions}

Conceived and designed the experiments: $S$ Noreen, Performed the Experiments: M Hussain, B Ijaz \& F Bilal, Analyzed the Data: S Noreen \& F Batool, Contributed reagents/ materials/ analysis tools: B Ijaz, Wrote the paper: S Noreen \& F Batool.

\section{References}

1. Izzo AA \& Ernst E (2009). Interaction between herbal medicines and prescribed drugs. Drugs 69: 1777-1798.

2. Alder JD (2005). Daptomycin, a new drug class for the treatment of Grampositive infections. Drugs Today 4: 81.
3. Walsh C (2003). Where will new antibiotics come from? Nat Reviews Micro 1: 65-70.

4. Koehn FE \& Carter GT (2005). The evolving role of natural products in drug discovery. Nat Rev Drug Discov 4: 206220.

5. Gogate VM (2000). Ayurvedic pharmacology and therapeutic uses of medicinal plants (Dravyaganvigyan), $1 s t$ ed. Mumbai: Bhartiya Vidya Bhavan.

6. Kirtikar KR \& Basu BD (1987). Indian medicinal plants. $2^{\text {nd }}$ Ed. Dehradun: International Book Distributors.

7. Paranjape P (2001). Indian medicinal plants. In: Forgotten healer: A guide to Ayurvedic herbal medicine. Delhi. Chaukhamba Sanskrit Pratisthan p: 1489.

8. Ghaisas M, Zope V, Takawale A, Navghare V, Tanwar M \& Deshpande A December (2010). Preventive effect of Sphaeranthus indicus during progression of glucocorticoid-induced insulin resistance in mice. 48: 1371-1375

9. Yadav RN \& Kumar S (1998). 7Hydroxy-3', 4', 5, 6-tetramethoxy flavone 7-O-b-D-(1-4)-diglucoside, a new flavone glycoside from the stem of Sphaeranthus indicus. J Inst Chem 70: 164-6.

10. Huie CW (2002). A review of modern sample-preparation techniques for the extraction and analysis of medicinal plants. Anal Bioanal Chem 373: 23-30.

11. Vinatoru M (2001). An overview of the ultrasonically assisted extraction of bioactive principles from herbs. Ultrason Sonochem 8: 303-313.

12. Duraipandiyan V, Kannan $\mathrm{P} \&$ Ignacimuthu S (2009). Antimicrobial Activity of Sphaeranthus indicus L. Ethnobot Leaflets 13: 320-5.

13. Nostro A, Germanò MP, Angelo VD, Marino A \& Cannatelli MA (2001). Extraction methods and bioautography for evaluation of medicinal plant 
antimicrobial activity. Lett Appl Microbiol 30: 379-384.

14. Sofowara A (1993). Medicinal plants and Traditional medicine in Africa. Spectrum Books Ltd, Ibadan, Nigeria pp. 289.

15. Rizk AM (1982). Constituents of Plants Growing in Qatar I.A. Chemical Survey of Sixty Plants. Fitoterapia 52: 35-42.

16. Edeoga HO, Okwu DE \& Mbaebie BO (2005). Phytochemical constituents of some Nigerian medicinal plants. Afr $J$ Biotechnol 4: 685-688.

17. Prasad S, Kashyap RS, Deopujari, JY, Purohit HJ, Taori GM \& Daginawala HF (2007). Effect of Fagonia Arabica (Dhamasa) on in vitro thrombolysis. BMC Complement Altern Med 7: 36.

18. Kim J, Marshall MR \& Wei CI (1995). Antibacterial activity of some essential oil components against five foodborne pathogens. J Agric Food Chem 43: 2839-2845.

19. Khan MM, Iqbal M, Hanif MA, Mahmood MS, Naqvi SA, Shahid M \& Jaskani MJ (2012). Antioxidant and antipathogenic activities of citrus peel oils. J Essent Oil Bear PL 15: 972-979.

20. Terigar BG, Balasubramanian S, Sabliov CM, Lima M \& Boldor D (2011). Soybean and rice bran oil extraction in a continuous microwave system: from laboratory to pilot scale. J Food Eng 104: 208-217.

21. Spigno G \& De FDM (2009). Microwave -assisted extraction of tea phenols a phenomenological study. $J$ Food Eng 93: 210-217.

22. Hayouni EA, Abedrabba M, Bouix M \& Hamdi M (2007). The effects of solvents and extraction method on the phenolic contents and biological activities in vitro of Tunisian Quercus coccifera L. and Juniperus phoenica L. fruit extracts. Food Chem 105: 1126-1134.

23. Ishida BK, Ma J \& Bock C (2001). A simple rapid method for HPLC analysis of lycopene isomers. Phytochem Anal 12: 194-198.

24. Mir MA, Sawhney SS \& Jassal MMS (2013). Qualitative and quantitative analysis of phytochemicals of Taraxacum officinale. Wudpecker J Med 2: 1-5.

25. Savithramma N, Linga Rao M \& Suhrulatha D (2011). Screening of Medicinal Plants for Secondary Metabolites. Middle East J Sci Res 8: 579-584.

26. Sultana B, Anwar F, Mushtaq M, Aslam $M$ \& Ijaz S (2014). In vitro antimutagenic, antioxidant activities and total phenolics of clove (Syzygium aromaticum L.) seed extracts. Pak J Pharm Sci 27: 893-899.

27. Dwivedi SK, Saran RK, Narain VS, Bansal S, Gupta R \& Puri VK (2000) Accelerated infusion ofstreptokinase in acute myocardial infarction results in better TIMI flow grade in infarct-related artery. Ind. Heart J 52: 40-44.

28. Bhattacharya S \& Roy B (2010). Preliminary investigation on antipyretic activity of Cuscuta reflexa in rats. $J A d v$ Pharm Technol Res 1: 83-87.

29. Chanda S \& Rakholiya. K (2011). Combination therapy: Synergism between natural plant extracts and antibiotics against infectious diseases. Science against microbial pathogens: communicating current research and technological advances A. Méndez-Vilas (Ed.) pp. 520-529. 